\title{
Improvements in the quality of care and health outcomes with new stroke care units following implementation of a clinician-led, health system redesign programme in New South Wales, Australia
}

\author{
D A Cadilhac, ${ }^{1,2}$ D C Pearce, ${ }^{1}$ C R Levi, ${ }^{3}$ G A Donnan, ${ }^{1,2,4}$ on behalf of the Greater \\ Metropolitan Clinical Taskforce and New South Wales Stroke Services Coordinating \\ Committee
}

- Additional figures and a table are published online only at http://qshc.bmj.com/content/ vol17/issue5

\footnotetext{
${ }^{1}$ National Stroke Research Institute, Austin Health, Heidelberg Heights, Victoria, Australia; ${ }^{2}$ Department of Medicine, University of Melbourne, Melbourne, Australia; ${ }^{3}$ Hunter Stroke Service, John Hunter Hospital, Newcastle, New South Wales, Australia; ${ }^{4}$ Neurology Department, Austin Health, Heidelberg Heights, Victoria, Australia
}

\section{Correspondence to:}

D A Cadilhac, National Stroke

Research Institute, Level 1 Neurosciences Building,

Repatriation Hospital, 300

Waterdale Road, Heidelberg

Heights, Victoria, Australia 3081;

dcadilhac@nsri.org.au

Accepted 12 November 2007

\section{ABSTRACT}

Background and objectives: Provision of evidencebased hospital stroke care is limited worldwide. In Australia, about a fifth of public hospitals provide stroke care units (SCUs). In 2001, the New South Wales (NSW) state government funded a clinician-led, health system redesign programme that included inpatient stroke services. Our objective was to determine the effects of this initiative for improving: (i) access to SCUs and care quality and (ii) health outcomes.

Design, setting and participants: Preinterventionpostintervention design (12 months prior and a minimum 6-12 months following SCU implementation).

Retrospective, public hospital audit of 50 consecutive medical records per time period of stroke admissions (using International Classification of Diseases (ICD)-10 codes). Combined analyses for 15 hospitals presented. Outcomes: Process of care indicators and patient independence (proportional odds modelling using modified Rankin scale).

Results: Pre-programme cases $(n=703)$ (mean (SD) age 74 (14) years; female: 51\%) and post-programme cases ( $n=884$ ) (mean age 74 (14) years; female: 49\%) were comparable. Significant post-programme improvements for most process indicators were found, such as more brain imaging within 24 hours. Post-programme, access to SCUs increased 22-fold (95\% Cl 16.8 to 28.3). Improvement in inpatient independence at post-programme discharge was significant compared with preprogramme outcomes (proportional odds ratio 0.73, 95\% $\mathrm{Cl} 0.57$ to $0.94 ; p=0.013$ ) when adjusted for patient clustering and case mix.

Conclusions: This distinctive SCU initiative was shown as effective for improving clinical practice and significantly reducing disability following stroke.

The burden of stroke is predicted to increase in both developed and developing countries. ${ }^{1}$ Stroke care units (SCUs), which provide geographically localised multidisciplinary management, are internationally recognised as the most generalisable and effective treatment for stroke. ${ }^{2}$ Although poorly documented, SCU availability in different countries seems to range between $4 \%$ and $70 \% .^{3}$ In Australia, about $19 \%$ of acute public hospitals have an SCU. ${ }^{4}$ Strategies for improving the establishment of SCUs have not been well described.

Although Australian national policy supports the establishment of SCUs, ${ }^{5}$ funding responsibilities are vested with separate state and territory governments. Therefore, low penetration of SCUs in this healthcare "system" suggested a significant policypractice gap. In 2001, the New South Wales (NSW) government (responsible for about a third of the Australian population) enacted a health system redesign programme to improve access to evidencebased healthcare. It was the first to provide substantial funding for SCUs. The Greater Metropolitan Clinical Taskforce (GMCT) was subsequently established to bring clinicians and consumers together to work with the government to drive the programme objectives for the greater Sydney $\operatorname{area}^{67}$ (fig 1).

The original objectives of the stroke programme included establishing a coordinating committee and nine stroke area "networks" with 19 SCUs in hospitals admitting at least 200 strokes per year. In addition, minimum standards of care were to be developed and staffing and clinical training reviewed. Education forums and opportunities for networks to share information, such as clinical protocols, were also undertaken. Establishment funding, expended by June 2003, was mainly used for employing staff, purchasing equipment and/or ward refurbishments. Operational recurrent funding of approximately AU $\$ 10$ million is ongoing. Prior to provision of establishment funding there were seven SCUs in the study region. In Australia, the length of stay for acute stroke care is typically between 10 and 11 days. Following the acute admission, patients are discharged home with or without additional outpatient rehabilitation services or they are discharged to an inpatient rehabilitation facility or to an aged care facility.

An external evaluation of the stroke programme was initiated with researchers from the National Stroke Research Institute (NSRI) (based outside NSW). The aims were to determine the effects of this programme for improving (i) access to SCUs and care quality and (ii) health outcomes by intention-to-treat, as well as for those receiving some or all of their care in an SCU.

\section{METHODS}

We used a preintervention-postintervention study design including consecutive audits of up to 50 medical records with a discharge International Classification of Diseases (ICD)-10 code for stroke 


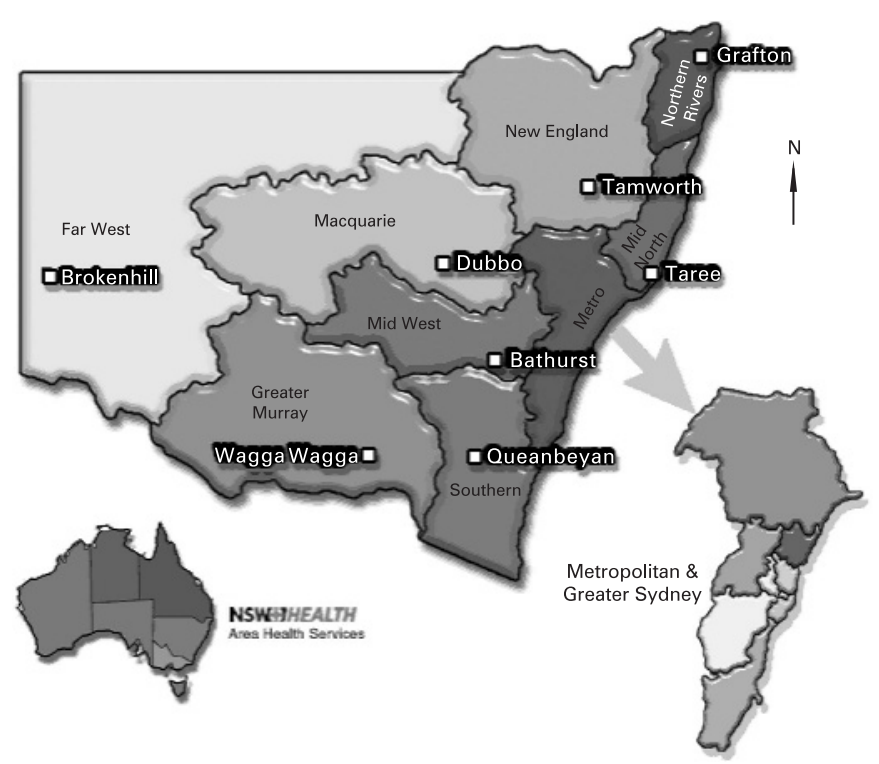

Figure 1 New South Wales stroke programme boundaries. Reprinted with permission from NSW Health, Australia.

for each time period. The pre-programme period was 12 months prior to the stroke programme commencing (mostly cases treated in 2001 and 2002). The post-programme period required cases to be admitted a minimum of 6-12 months following service enhancements (between 2003 and 2005). SCUs providing pre and post data by December 2006 which had received enhancement funding were included in this analysis $(n=15)$. Participation was voluntary and permission from the hospital administrators was obtained. Where required, approval by a human research and ethics committee was gained.

To maintain privacy, patient data were de-identified and only aggregated data are presented. Patient eligibility criteria were: diagnosis of stroke (ischaemic or haemorrhagic stroke); acute symptoms lasting more than $24 \mathrm{~h}$; admission to hospital; and availability of the medical record for audit.

\section{Data collection}

An audit tool was developed that included clinical performance indicators advocated by the National Stroke Foundation $(\mathrm{n}=9)$ and endorsed by the Australian Government, ${ }^{8}$ as well as high priority indicators previously reported by the NSRI. ${ }^{9}$ A range of measures were incorporated relevant to medical, nursing and allied health clinicians, such as brain imaging, allied health assessments, neurological observations, and reflecting timing of interventions, types of intervention and facilitators of better management (eg, use of clinical management plans).

For consistent data abstraction, participating hospital staff were trained by the GMCT stroke programme manager (previously trained by the NSRI). Completed audits were processed at the NSRI. Programmed data logic checks were implemented to verify the data (eg, date ranges and subcategory responses to primary questions). Inter-rater reliability was assessed by undertaking a $10 \%$ random audit of medical records in two of the hospitals, using a blinded and independent assessor.

\section{Study end points}

The primary end point reflects level of impairment following stroke and was based on the modified Rankin scale (mRS) ${ }^{11}$ score at discharge or 7-10 days after the stroke (range 0-6, 0 indicating no residual symptoms through sequential levels of disability to 6 indicating death). Secondary outcomes included adherence to individual process indicators as explanatory variables and proportion of severe complications.

\section{Definitions}

\section{Process indicators}

- Admission to SCUs: percentage of patients admitted from the emergency department.

- Access to SCUs: percentage of patients spending some time in an SCU.

- Brain imaging: both CT and MRI.

- Swallowing ability: documentation by any health professional.

- Adherence rates: reflects care that should have been given (number of cases adhered/total applicable cases).

- Clinical care plan: evidence of a written plan by health professionals.

- Clinical pathway: structured tool detailing the activities of care during hospital admission.

\section{Outcomes}

- Independence at discharge: mRS 0-2 $2^{2}$

- Severe complications: any new medical condition occurring during hospitalisation and considered incapacitating, lifethreatening or resulting in a prolonged stay or increased patient acuity.

\section{Statistical analysis}

Intention-to-treat and "on-treatment" (cases receiving some, or all of their care, in an SCU) analyses were undertaken for preprogramme-post-programme comparisons. Data were analysed using STATA version 8.0. $\chi^{2}$ tests were used for categorical variables, Fisher exact test for dichotomous variables, and the Mann-Whitney test for skewed continuous variables. Patient outcomes were investigated using ordered logistic regression to estimate the proportional odds ratio over all levels of the $\mathrm{mRS}$ (Stata Annotated Output: Ordered Logistic Regression; http:// www.ats.ucla.edu/stat/stata/output/stata_ologit_output.htm; retrieved on 28 January 2007). Logistic regression was also used for dichotomous patient outcomes.

Adjustment for patient case mix was based on a validated prognostic model ${ }^{11}$ when comparing patient outcomes. These variables included independence prior to stroke ( $\mathrm{mRS} 0$ or 1), age, arm deficit, speech impairment, incontinence (within $72 \mathrm{~h}$ ), and ability to walk unaided on admission. Adjustment was also made for patient clustering within hospitals.

Inter-rater reliability was assessed with the $\kappa$ statistic. Agreement between observers was deemed to be excellent if $\kappa>0.8$, good if $\kappa>0.6 \leqslant 0.8$ and moderate if $\kappa>0.4 \leqslant 0.6$. The level of significance was $\mathrm{p}<0.05$.

\section{RESULTS}

Fifteen hospitals contributed 1587 cases (pre-programme: 703 and post-programme: 884). Baseline demographic characteristics and stroke severity status were mostly comparable across the time periods (exceptions: history of hypertension and incontinence within $72 \mathrm{~h}$ ). The mean (SD) age of the patients was 74 (14) and about half were men. When pre-programme cases were compared with post-programme patients treated in SCUs (mean age 78 (13) years, women 48\%) the only significant difference was more pre-stroke independence in the postprogramme SCU group (table 1). 
Table 1 Patient demographics and baseline stroke severity by audit period and treatment in a stroke care unit

\begin{tabular}{|c|c|c|c|}
\hline Baseline characteristics & $\begin{array}{l}\text { Pre-programme } \\
(\mathrm{n}=703) \\
\mathrm{n}(\%)\end{array}$ & $\begin{array}{l}\text { Post-programme } \\
\text { (PP) (n= 884) } \\
\text { n (\%) }\end{array}$ & $\begin{array}{l}\text { Stroke unit care } \\
\mathrm{PP}(\mathrm{n}=719) \\
\mathrm{n}(\%)\end{array}$ \\
\hline Age mean $(S D) \dagger$ & $74(14)$ & $74(14)$ & $73(14)$ \\
\hline Women: & $355(51)$ & $427(49)$ & $343(48)$ \\
\hline Australian§ & $436(65)$ & $587(69)$ & $466(68)$ \\
\hline Married/with partner†† & $313(51)$ & $440(54)$ & $374(56)$ \\
\hline $\begin{array}{l}\text { Independent prior to stroke } \\
(\mathrm{mRS} 0-1) \ddagger\end{array}$ & $475(69)$ & $617(71)$ & $527(74)^{*}$ \\
\hline Atrial fibrillation§ & $156(24)$ & $219(28)$ & $177(27)$ \\
\hline Hypercholesterolaemia§ & $196(30)$ & $263(33)$ & $223(34)$ \\
\hline Hypertension & $413(62)$ & $566(68)^{*}$ & $455(67)^{* *}$ \\
\hline Diabetes & $141(21)$ & $184(23)$ & $154(23)$ \\
\hline Ischaemic heart disease & $198(29)$ & $252(30)$ & $201(29)$ \\
\hline Previous TIA & $85(13)$ & $122(15)$ & $92(14)$ \\
\hline Previous stroke & $177(26)$ & $190(23)$ & $145(21)$ \\
\hline \multicolumn{4}{|c|}{ Stroke subtypes (0xford classification) $\$$} \\
\hline Ischaemic stroke & $651(94)$ & $806(93)$ & $663(94)$ \\
\hline $\mathrm{TACl}$ & $120(24)$ & $138(26)$ & $165(23)$ \\
\hline $\mathrm{PACl}$ & $206(41)$ & $184(35)$ & $248(35)$ \\
\hline LACl & $89(18)$ & $126(24)$ & $177(25)$ \\
\hline $\mathrm{POCl}$ & $60(12)$ & $58(11)$ & $73(10)$ \\
\hline Haemorrhagic stroke & $45(7)$ & $64(7)$ & $44(6)$ \\
\hline \multicolumn{4}{|c|}{ Stroke severity (case mix adjustment) variables } \\
\hline $\begin{array}{l}\text { Impaired speech (SSS } \\
\text { speech score } 0,3,6)\end{array}$ & $458(70)$ & $590(69)$ & $484(70)$ \\
\hline $\begin{array}{l}\text { Weak arm (SSS score } \\
0,2,4 \text { or } 5) \S\end{array}$ & $522(77)$ & $669(77)$ & $550(77)$ \\
\hline $\begin{array}{l}\text { Able to walk on admission } \\
\text { (SSS gait score } 0,3 \text { or } 6) \dagger\end{array}$ & $219(36)$ & $280(35)$ & $237(37)$ \\
\hline $\begin{array}{l}\text { Incontinent }<72 \mathrm{~h} \text { after } \\
\text { stroke§ }\end{array}$ & $318(47)$ & $356(41)^{*}$ & $277(39)^{*}$ \\
\hline
\end{tabular}

${ }^{*} \mathrm{p}<0.05 ;{ }^{*} \mathrm{p}<0.07$.

$\dagger<1 \%$ missing; $\$<3 \%$ missing; $\S<5 \%$ missing; $-<10 \%$ missing or unknown; $\dagger+<15 \%$ missing. LACl, lacunar infarct; mRS, modified Rankin scale; PACI, partial anterior circulation infarct; POCl, posterior circulation infarct; SSS, Scandinavian stroke scale; $\mathrm{TACl}$, total anterior circulation infarct; TIA, transient ischaemic attack.

Inter-rater reliability testing indicated key variables used for case mix adjustment, subgroup classification or as process indicators as generally demonstrating excellent or good agreement. Poor agreement was noted for ability to walk on admission, discharge delays, premorbid $\mathrm{mRS}$ and use of care plans.

\section{Influence of programme on patient outcomes}

There was significant post-programme improvement across all levels of the mRS scores at discharge or 7-10 days after the stroke compared with patient outcomes pre-programme (table 2 and fig 2). Post-programme patients experienced fewer disabling outcomes (proportional odds ratio adjusted for case-mix and patient clustering OR $0.73 ; 95 \%$ CI 0.57 to 0.94 ). This result was further improved in post-programme patients receiving treatment in an SCU. When the mRS was dichotomised, the odds of being independent at discharge (mRS 0-2) improved postprogramme (odds ratio (OR) 1.31, 95\% CI 1.07 to 1.63 ) and was better if treated in SCUs (OR 1.39, 95\% CI 1.12 to 1.74). However, adjustment for case mix and patient clustering eliminated the statistical significance (intention-to-treat OR $1.47,95 \%$ CI 0.94 to 2.30 ; on-treatment OR $1.48,95 \%$ CI 0.93 to 2.35). Treatment in an SCU also reduced the odds of severe complications (OR $0.55,95 \%$ CI 0.37 to 0.82 ). However, the statistical significance was again lost with adjustments for patient case mix and clustering (OR $0.67,95 \%$ CI 0.32 to 1.39).
Discharge day 7-10 modified Rankin scores

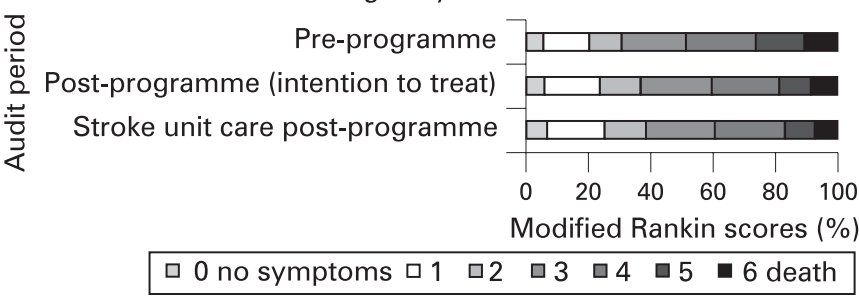

Figure 2 Modified Rankin scores at discharge.

\section{Clinical management between audit periods}

Prior to the programme, only $13 \%$ of cases were admitted to SCUs from the emergency department, whereas post-programme, 71\% were directly admitted (OR 16.8, 95\% CI 12.8 to 22.0). There was also a 22 -fold increase for treatment in an SCU (admitted or transferred during admission) between the time periods (pre-programme 17\% versus post-programme $81 \%$, OR, 21.8; 95\% CI 16.8 to 28.3). If treated in SCUs, most patients received at least $50 \%$ of their care in SCUs regardless of time period (pre-programme $86 \%$ and post-programme $89 \%$ ).

Compared with pre-programme estimates, significant postprogramme improvements were found for most process of care indicators. These improvements were consistently more pronounced if the patients were treated in SCUs (table 3). Postprogramme patients were three times more likely to have brain imaging (OR 3.1, 95\% CI 1.8 to 5.2) and twice as likely to have regular neurological observations (OR 2.35, 95\% CI 1.6 to 3.4 ) within $24 \mathrm{~h}$ of admission. Post-programme cases received more allied health assessments (OR 2.4, 95\% CI 1.5 to 3.6) and more family meetings within 7 days of admission (OR 3.7, 95\% CI 1.1 to 12.3). If treated in an SCU with ischaemic stroke, the odds of receiving aspirin within $24 \mathrm{~h}$ as new treatment were $76 \%$ increased (OR 1.76, 95\% CI 1.41 to 2.19) and a $38 \%$ greater chance of being discharged on anti-thrombotic therapy (OR $1.38,95 \%$ CI 1.02 to 1.87$)$.

Overall, approximately $3-5 \%$ of patients received palliative care and about $10 \%$ died in hospital. Median length of stay was about 9 days. More post-programme patients were discharged home and there was a reduction in inpatient admissions for rehabilitation (table 4).

\section{DISCUSSION}

Important changes in clinical practice and patient outcomes were identified following investment in stroke services in the Greater Metropolitan Area of NSW. In particular, the study provided evidence that better access to important aspects of organised stroke care such as timely and early allied health assessments, brain imaging and appropriate use of aspirin, which are consistent with current clinical practice guideline recommendations. ${ }^{12}$ These improvements were supported by increased use of care planning and admissions to localised SCUs. The increased access to SCUs with better adherence to important clinical processes of care resulted in about a third of patients following stroke having improved outcomes compared with pre-programme estimates. These findings are consistent with other similar observational studies. ${ }^{13-16}$

The proportional odds modelling using the mRS was chosen as the more precise method of analysing the outcome data between programme time periods rather than using a dichotomous cutpoint. ${ }^{17} 18$ Indeed, the importance of the stroke programme and subsequent better effectiveness of SCUs was evidenced more clearly, in a demonstrated shift away from 
Table 2 Result of the ordered logistic regression models used to estimate the proportional odds ratios for modified Rankin score (dependent variable) at discharge or 7-10 days after the stroke

\begin{tabular}{|c|c|c|}
\hline Variable & Odds ratio $\left(95 \% \mathrm{Cl}^{*}\right)$ & p Value \\
\hline \multicolumn{3}{|l|}{ Intention-to-treat analysis } \\
\hline $\begin{array}{l}\text { Post-programme vs pre-programme } \uparrow \\
\text { (univariate) }(n=1570)\end{array}$ & $0.74(0.56$ to 0.98$)$ & 0.038 \\
\hline $\begin{array}{l}\text { Post-programme vs pre-programme } \\
(\mathrm{n}=1256)\end{array}$ & $0.73(0.57$ to 0.94$)$ & 0.013 \\
\hline Arm deficit: & $2.40(1.78$ to 3.23$)$ & $<0.001$ \\
\hline Impaired speech & $1.94(1.55$ to 2.42$)$ & $<0.001$ \\
\hline Walk on admission§ & $0.39(0.28$ to 0.55$)$ & $<0.001$ \\
\hline Incontinent $<72 \mathrm{~h}$ of stroke & 6.08 (4.62 to 7.99$)$ & $<0.001$ \\
\hline Age at stroke $\dagger$ & $1.03(1.03$ to 1.04$)$ & $<0.001$ \\
\hline Independent prior to stroke $\ddagger$ (mRS $0-1)$ & $0.56(0.39$ to 0.81$)$ & 0.002 \\
\hline \multicolumn{3}{|c|}{ Analysis for patients treated only in an SCU compared with pre-programme } \\
\hline $\begin{array}{l}\text { SCU-only post-programme vs pre-programme } \dagger \\
\text { (univariate) }(\mathrm{n}=1407)\end{array}$ & $0.68(0.49$ to 0.94$)$ & 0.020 \\
\hline $\begin{array}{l}\text { SCU-only post-programme vs pre-programme } \\
(\mathrm{n}=1126)\end{array}$ & $0.69(0.53$ to 0.91$)$ & 0.007 \\
\hline Arm deficit: & 2.33 (1.72 to 3.15$)$ & $<0.001$ \\
\hline Impaired speech $\ddagger$ & 1.99 (1.58 to 2.51$)$ & $<0.001$ \\
\hline Walk on admission§ & $0.39(0.28$ to 0.54$)$ & $<0.001$ \\
\hline Incontinent $<72 \mathrm{~h}$ of stroket: & 5.95 (4.85 to 7.29$)$ & $<0.001$ \\
\hline Age at stroke $\dagger$ & 1.03 (1.027 to 1.039$)$ & $<0.001$ \\
\hline $\begin{array}{l}\text { Independent prior to stroke: } \\
\text { (mRS 0-1) }\end{array}$ & $0.59(0.40$ to 0.85$)$ & 0.005 \\
\hline
\end{tabular}

${ }^{*}$ Adjusted for clustering of cases within hospitals; $\uparrow<1 \%$ cases missing in either group; $₫<5 \%$ cases missing in either group; $\S<8 \%$ cases missing in either group. SCU, stroke care unit.

higher scores (worse outcomes) towards lower scores (greater independence) (see online supplementary data for web-only table and fig for estimated "modelled" prediction scores). The power to detect differences in the occurrences of severe complications was compromised by a low event-to-variable ratio.

As this was a pragmatic audit, hospital-based clinicians collected the data. Nonetheless, the data collected were shown to be reproducible by an independent and blinded auditor. This has also been demonstrated in another similar study. ${ }^{19}$ Other potential sources of reporting bias include abstracting process of care data from medical records, which may not have been routinely recorded or required subjective judgements. Steps to minimise bias included using external investigators to analyse the data, supplying a data dictionary and consistent auditor training. Other limitations include the possibly better recording of process data and outcomes given improved use of clinical management plans. In addition, changes in clinical practice may have occurred over time irrespective of the programme. These factors may be overestimating the effects of the programme, but as the effects are mostly large, this cannot explain all the differences. Furthermore, the sampling strategy was nonrandom and this may have led to biased estimates of effects and differences between comparator groups. However, the approach of using consecutive admissions is consistent with other similar research in this field. ${ }^{16}$

We acknowledge that in the univariate analyses presented for demography, risk factors and indicators of stroke severity (table 1), a spurious statistically significant finding was probably because of the conduct of multiple comparisons. The observed differences while significant at the 0.05 level were small enough to justify the assumption of comparability of the two cohorts. Further, we have made adjustment for differences in case mix in multivariate analyses. The coherence between the magnitude of the impacts of the intervention were consistent across processes of care and patient outcomes, providing confirmatory evidence that these findings are valid.

Table 3 Adherence to applicable clinical care processes as a measure of care quality

\begin{tabular}{|c|c|c|c|}
\hline Processes of care indicators & $\begin{array}{l}\text { Pre-programme } \\
(\mathrm{n}=703) \\
\mathrm{n}(\%)\end{array}$ & $\begin{array}{l}\text { Post-programme } \\
\text { (PP) (n = 884) } \\
\text { n (\%) }\end{array}$ & $\begin{array}{l}\text { Stroke unit care } \\
\operatorname{PP}(n=712) \\
n(\%)\end{array}$ \\
\hline \multicolumn{4}{|l|}{ Within $24 \mathrm{~h}$} \\
\hline Brain imaging $\dagger$ & $618(89)$ & $844(96)^{*}$ & $681(96)^{*}$ \\
\hline Documentation of swallowing $\$$ & $387(56)$ & $623(73)^{*}$ & $525(75)^{*}$ \\
\hline $\begin{array}{l}\text { Documentation of swallowing if admitted } \\
\text { with impaired speech }\end{array}$ & $272 / 458(59)$ & $430 / 590(73)^{*}$ & $364 / 484(76)^{*}$ \\
\hline $\begin{array}{l}\text { Aspirin if ischaemic stroke and not } \\
\text { previously on aspirin }\end{array}$ & 196/378 (52) & $284 / 436(65)^{*}$ & $238 / 368(65)^{*}$ \\
\hline \multicolumn{4}{|l|}{ General management } \\
\hline Admitted to stroke unit§ & $85(13)$ & $623(71)^{*}$ & $623(88)^{*}$ \\
\hline Any care in a stroke unit during admission & $109(16)$ & $712(81)^{*}$ & $712(100)^{*}$ \\
\hline Palliative care§ & $32(5)$ & $44(5)$ & $21(3)$ \\
\hline Allied health assessment $\uparrow$ & $639(91)$ & $848(96)^{*}$ & $696(98)^{*}$ \\
\hline Physiotherapy: & $573(83)$ & $775(89)^{*}$ & $650(92)^{*}$ \\
\hline Within $48 \mathrm{~h}$ admissiont: & $296(43)$ & $530(61)^{*}$ & $449(64)^{*}$ \\
\hline Speech therapy: & $505(73)$ & $717(82)^{*}$ & $601(86)^{*}$ \\
\hline Within $48 \mathrm{~h}$ admission & $381(55)$ & $571(66)^{*}$ & $487(69)^{*}$ \\
\hline Occupational therapy§ & $487(72)$ & $725(84)^{*}$ & $619(88)^{*}$ \\
\hline Within $48 \mathrm{~h}$ admission§ & $172(25)$ & $386(45)^{*}$ & $348(50)^{*}$ \\
\hline Any allied health within $48 \mathrm{~h}$ & $516(73)$ & $728(82)^{*}$ & $602(85)^{*}$ \\
\hline $\begin{array}{l}\text { Family meeting within } 7 \text { days with } \\
\text { multidisciplinary team } 甘\end{array}$ & $58(8)$ & $226(26)^{*}$ & $204(29)^{*}$ \\
\hline $\begin{array}{l}\text { Clinical care plan to avoid complications and } \\
\text { urinary incontinencet }\end{array}$ & $309(45)$ & $592(67)^{*}$ & $514(72)^{*}$ \\
\hline Clinical pathway during admission: & $110(16)$ & $494(56)^{*}$ & $459(65)^{*}$ \\
\hline
\end{tabular}

${ }^{*} \mathrm{p}<0.05$.

$\dagger<1 \%$ missing; $\uparrow<3 \%$ missing; $\S<5 \%$ missing; " derived variable where missing or "unknown" data was assumed to be "no". 
Table 4 Summary of univariate discharge and outcome variables

\begin{tabular}{|c|c|c|c|}
\hline Discharge process and outcome variables & $\begin{array}{l}\text { Pre-programme } \\
(\mathrm{n}=703) \\
\mathrm{n}(\%)\end{array}$ & $\begin{array}{l}\text { Post-programme } \\
\text { (PP) (n= 884) } \\
\text { n (\%) }\end{array}$ & $\begin{array}{l}\text { Stroke unit care } \\
\mathrm{PP}(\mathrm{n}=712) \\
\mathrm{n}(\%)\end{array}$ \\
\hline Number discharged $(\%) \dagger$ & $626(89)$ & $795(90)$ & $655(92)^{* *}$ \\
\hline \multicolumn{4}{|l|}{ Discharge process indicators } \\
\hline Discharge strategy (if discharged)§ & $332(56)$ & $526(69)^{*}$ & $440(70)$ \\
\hline $\begin{array}{l}\text { Antithrombotic agent if ischaemic stroke and not previously } \\
\text { taking antithrombotics }\end{array}$ & $200(57)$ & $253(63)$ & $223(65)^{*}$ \\
\hline Self-management care plan (if discharged) $\%$ & $68(11)$ & $179(23)^{*}$ & $162(25)^{*}$ \\
\hline Evidence of patient education if no self- management plan & $108(25)-$ & $182(34)^{*}+\dagger$ & $166(38)^{*} \dagger \dagger$ \\
\hline \multicolumn{4}{|l|}{ Discharge outcome variables } \\
\hline Length of stay median $(01,03)$ (all cases) $)$ \# & $9(5,18)$ & $9(5,19)$ & $10(6,20)$ \\
\hline Discharge delay & $108(18)$ & $129(16)$ & $119(18)$ \\
\hline Independent at discharge (mRS $0-1) \$$ & $141(20)$ & $206(24)^{*}$ & $177(25)^{*}$ \\
\hline \multicolumn{4}{|l|}{ Medical complications: } \\
\hline Falls & $77(11)$ & $60(7)^{*}$ & $49(7)^{*}$ \\
\hline Aspiration pneumonia & $34(5)$ & $45(5)$ & $36(5)$ \\
\hline Urinary tract infections & $85(12)$ & $87(10)$ & $75(11)$ \\
\hline Decubitus ulcers & $16(2)$ & $9(1) * *$ & $7(1)$ \\
\hline Any severe complication & $70(10)$ & $62(7)^{*}$ & $40(6)^{*}$ \\
\hline \multicolumn{4}{|l|}{ Discharge destination (survivors) } \\
\hline Home/relatives home & $269(44)$ & $407(52)^{*}$ & $336(52)^{*}$ \\
\hline Rehabilitation & $193(31)$ & $200(26)^{*}$ & $171(27) * *$ \\
\hline Aged care facility & $157(25)$ & $179(23)$ & $138(21)$ \\
\hline
\end{tabular}

${ }^{*} \mathrm{p}<0.05$; ${ }^{* *} \mathrm{p}<0.07 . \dagger<1 \%$ missing; $\uparrow<3 \%$ missing; $\S<5 \%$ missing; $\uparrow<10 \%$ missing data; $\dagger \uparrow 22 \%$ of data missing; $\uparrow$ tho adjustments for outliers were made.

\section{CONCLUSION}

We have been able to highlight improvements in the quality of care as a consequence of the NSW GMCT stroke programme being implemented. The success of the GMCT stroke unit programme has resulted from, among other things, effective implementation of a governmental health policy by the development of a strong partnership between stroke clinicians and health service management. An important initial incentive to form this partnership was resource allocation to establish or enhance SCUs. Better patient outcomes were clearly observed associated with greater adherence to evidence-based practice. Individual hospital stroke services also possibly benefited from the audits by using their individual results to focus additional improvements in stroke care at their centres. Audit and feedback cycles can be effective at changing clinical practice. ${ }^{20}$ With continuing demonstration of the effectiveness of such programmes, hopefully more Australian states, and other countries where access to SCUs is not universal, will invest in initiatives to forge partnerships between stroke clinicians and health service management resulting in improved access to SCUs.

Acknowledgements: The involvement of the hospital staff, and the assistance and cooperation of the Stroke Program State Manager, Mark Longworth, and the Area Stroke Clinical Nurse Consultants is acknowledged. We also acknowledge the area directors of Stroke Services across the GMCT network for supporting this work: C Storey, D Crimmins, J Sturm, M Pollack, A Zagami, D Serisier, A Corbett, A McDougall, J Wood and P Landau. The authors thank S Morrisey, B Quang, N Chivatas and A Young for their contribution to data processing. We also thank $L C$ Quang for her contribution to teleform questionnaire development and database management. J Stork is acknowledged for her contribution as the blinded independent auditor.

Funding: The GMCT evaluation was supported by New South Wales Health, which was facilitated by the Greater Metropolitan Clinical Taskforce and the New South Wales Stroke Services Network Coordinating Committee.

Competing interests: $\mathrm{CL}$ is the head of one of the dedicated stroke units involved in this study. However, he was not directly involved in the collection of data or analysis of the results.

\section{REFERENCES}

1. Strong K, Mathers C, Leeder S, et al. Preventing chronic diseases: how many lives can we save? Lancet 2005;366:1578-82.
2. Stroke Unit Trialists' Collaboration. Organised inpatient (stroke unit) care for stroke. Oxford: Update Software. Cochrane Database Syst Rev 2003(1):CD000197.

3. Rudd AG, Matchar DB. Health policy and outcome research in stroke. Stroke 2004;35:397-400.

4. Cadilhac DA, Lalor EE, Pearce DC, et al. Access to stroke care units in Australian public hospitals: facts and temporal progress. Intern Med J 2006;36:700-4.

5. National Heart Stroke and Vascular Health Strategies Group. National strategy for heart, stroke and vascular health in Australia. Canberra: Australian Government Department of Health and Ageing, 2004:31.

6. Stewart GJ, Dwyer JM, Goulston KJ. The Greater Metropolitan Clinical Taskforce: an Australian model for clinician governance. Med J Aust 2006;184:597-8.

7. Braithwaite J, Goulston K. Turning the health system 90 degrees down under. Lancet 2004;364:397-9.

8. National Stroke Foundation. Stroke services in Australia: National Stroke Unit Program policy document. Melbourne: National Stroke Foundation, 2002.

9. Cadilhac DA, Ibrahim J, Pearce DC, et al. Multicenter comparison of processes of care between stroke units and conventional care wards in Australia. Stroke 2004;35:1035-40.

10. van der Walt A, Gilligan AK, Cadilhac DA, et al. Quality of stroke care within a hospital: effects of a mobile stroke service. Med J Aust 2005;182:160-3.

11. Bamford JM, Sandercock PA, Warlow CP, et al. Interobserver agreement for the assessment of handicap in stroke patients. Stroke 1989;20:828.

12. Counsell C, Dennis M, McDowall M, et al. Predicting outcome after acute and subacute stroke: development and validation of new prognostic models. Stroke 2002;33:1041-7.

13. National Stroke Foundation. National guidelines for acute stroke management. Melbourne: National Stroke Foundation, 2003.

14. Glader EL, Stegmayr B, Johansson L, et al. Differences in long-term outcome between patients treated in stroke units and in general wards: a 2-year follow-up of stroke patients in Sweden. Stroke 2001;32:2124-30.

15. Stegmayr B, Asplund K, Hulter-Asberg K, et al. Stroke units in their natural habitat. Can results of randomized trials be reproduced in routine clinical practice? Stroke 1999;30:709-714.

16. Rudd AG, Hoffman A, Irwin P, et al. Stroke units: research and reality. Results from the National Sentinel Audit of Stroke. Qual Saf Health Care 2005;14:7-12.

17. Valenta Z, Pitha J, Poledne R. Proportional odds logistic regression-effective means of dealing with limited uncertainty in dichotomizing clinical outcomes. Stat Med 2006;25:4227-34.

18. Lees KR, Zivin JA, Ashwood T, et al. NXY-059 for acute ischemic stroke. N Engl J Med 2006;354:588-600.

19. Rudd AG, Hoffman A, Irwin P, et al. Stroke unit care and outcome: results from the 2001 National Sentinel Audit of Stroke (England, Wales, and Northern Ireland). Stroke 2005;36:103-6.

20. Grimshaw JM, Thomas RE, MacLennan G, et al. Effectiveness and efficiency of guideline dissemination and implementation strategies. Health Technol Assess 2004;8:iii-iv, 1-72. 